\title{
Article
}

\section{Characterisation of the steady state tube furnace (ISO TS 19700) for fire toxicity assessment}

Stec, Anna A, Hull, T Richard and Lebek, K

Available at http://clok.uclan.ac.uk/1084/

Stec, Anna A ORCID: 0000-0002-6861-0468, Hull, T Richard ORCID: 00000002-7970-4208 and Lebek, K (2008) Characterisation of the steady state tube furnace (ISO TS 19700) for fire toxicity assessment. Polymer Degradation and Stability, 93 (11). pp. 2058-2065. ISSN 01413910

It is advisable to refer to the publisher's version if you intend to cite from the work. http://dx.doi.org/10.1016/j.polymdegradstab.2008.02.020

For more information about UCLan's research in this area go to http://www.uclan.ac.uk/researchgroups/ and search for <name of research Group>.

For information about Research generally at UCLan please go to http://www.uclan.ac.uk/research/

All outputs in CLoK are protected by Intellectual Property Rights law, including Copyright law. Copyright, IPR and Moral Rights for the works on this site are retained by the individual authors and/or other copyright owners. Terms and conditions for use of this material are defined in the policies page.

\section{CLoK}

Central Lancashire online Knowledge www.clok.uclan.ac.uk

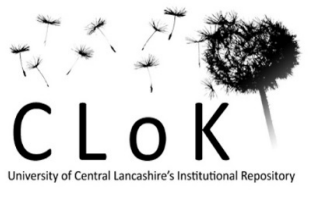




\title{
CHARACTERISATION OF
}

\section{THE STEADY STATE TUBE FURNACE (ISO TS 19700) FOR FIRE TOXICITY ASSESSMENT}

\author{
Anna A. Stec ${ }^{1}$, T. Richard Hull ${ }^{1 *}$, Krzysztof Lebek $^{2}$, \\ ${ }^{1}$ Centre for Fire and Hazards Science, University of Central Lancashire, Preston, PR1 2HE, UK. \\ ${ }^{2}$ Centre for Materials Research and Innovation, University of Bolton, Deane Road, Bolton, BL3 5AB, \\ UK. \\ *Corresponding Author: Email aastec@uclan.ac.uk \\ Voice +44 (0)1772 893759 \\ Fax $+44(0) 1772894981$
}

\begin{abstract}
The steady state tube furnace (Purser furnace, ISO TS 19700) has been developed specifically to replicate the generation of toxic products from real fires under different fire conditions on a bench scale. Steady state burning is achieved by driving the sample into a furnace of increasing heat flux at a fixed rate and recording the product yields over a steady state period in the middle of the run. The furnace, sample, and effluent dilution chamber temperature profiles are presented to characterise the conditions in the apparatus. The distribution of smoke in the mixing chamber has been investigated to demonstrate the efficiency of mixing in the effluent dilution chamber. The heat flux applied to the sample at various points through the furnace has been measured, showing that conditions vary from those typical of preflaming to fully-developed fires. An initial investigation of the repeatability and interlaboratory reproducibility has been undertaken, showing acceptable low levels of uncertainty in the toxic product yields.
\end{abstract}

\section{Introduction}

The majority of fire deaths are caused by inhalation of toxic gases, such as carbon monoxide, hydrogen cyanide and other products of incomplete combustion ${ }^{1}$. Different materials produce different toxic gases and the widespread use of polymers has increased the toxic hazard from fire. Flame retarded polymers, once ignited, may 
change the fire environment dramatically ${ }^{2}$. A major difficulty of predicting fire hazards is related to reliable prediction of toxic product yields that are strongly dependant on both material and fire conditions. The ultimate solution is to run large scale experiments, but the variety of fire scenarios, the cost and set-up time needed are often prohibitive. Fire hazard is a combination of flammability and fire smoke toxicity. While flammability has been extensively studied, fire smoke toxicity is difficult to replicate on a bench-scale, and tends to have been somewhat neglected. This illustrates the need to develop equipment capable of replicating real fires in order to provide data on fire toxicity to inform building and other regulators concerned with fire safety.

Most bench-scale fire models can only replicate the early stages of fire development, using small samples under open ventilation. However, the steady state tube furnace is capable of replicating each fire stage, from oxidative pyrolysis and well-ventilated flaming, right through to under-ventilated flaming, which is most difficult to replicate on a small scale, but the stage which causes most fire toxicity deaths.

The steady state tube furnace (BS $7990^{3}$ and ISO TS $19700^{4}$ ) is both a standard test method and a research tool that can provide building engineers and designers with valuable data related to fire hazard. The significant advantage of the apparatus over other techniques is its capability to replicate the whole range of fire conditions.

Extensive research, reviewed by $\mathrm{Pitts}^{5}$, on prediction of carbon monoxide evolution from flames of simple hydrocarbons, has shown the importance of the equivalence ratio $\phi$ (Equation 1).

$$
\phi=\frac{\text { actual fuel / air ratio }}{\text { stoichiometric fuel / air ratio }} \quad \text { Equation } 1
$$

Typically, for well-ventilated fires $\phi$ is less than 0.7 , while for fuel-rich (vitiated) combustion $\phi$ is greater than 1.5. In a fully developed fire, with low ventilation, $\phi$ can be as large as 5. For many hydrocarbon polymers, the CO yield increases rapidly with increase in $\phi$, and is almost independent of polymer ${ }^{6}$. In the steady tube furnace the ventilation can be characterized in terms of the equivalence 
ratio, based on the oxygen requirement for "stoichiometric" combustion to $\mathrm{CO}_{2}$ and water.

In order to understand the behaviour of the tube furnace, and its sensitivity to different experimental parameters, it was necessary to characterise the apparatus in terms of temperature profiles, the mixing inside the main parts of the apparatus, repeatability and reproducibility.

The steady state tube furnace (Purser furnace) ${ }^{7,8}$ is a bench scale test apparatus consisting of a tube furnace through which a sample is driven at a fixed rate, while being supplied with a fixed flow of primary air in order to replicate different ventilation conditions (Figure 1). By control of the sample feed rate, the temperature inside the furnace, and the air flow rate, different fire stages can be replicated, so the yields for oxidative pyrolysis (smouldering), well-ventilated and small and fully developed under-ventilated flaming can be obtained separately ${ }^{9}$. The effluent from the tube is made up to 50 litres per minute with secondary air, by dilution within the effluent dilution chamber. By fixing the fuel and primary air feed rates, the equivalence ratio can be controlled. An early version of this apparatus appeared as the IEC 60695-7-50 standard $^{10}$, which defines extremes of under- and over-ventilation, by volume of air per unit mass of sample (e.g. well ventilated used 22.6 litres $\min ^{-1}$ while underventilated used 2.6 litres $\min ^{-1}$ ). BS 7990 and ISO TS 19700 use the more sophisticated equivalence ratio approach, where the oxygen requirement is determined using $\phi=0.7$ for well-ventilated flaming and twice the stoichiometric fuel/air ratio $(\phi=2.0)$ for under-ventilated conditions.

As the sample is driven into the furnace, under an increasing applied heat flux, combustion is forced, even under reduced ventilation. After ignition occurs, the flame with stabilise in a part of the furnace close to the pilot ignition temperature of the sample. The toxic product yield data is taken over the steady period of the run, when the burning behaviour has stabilised after ignition. A paramagnetic oxygen analyser, NDIR $\mathrm{CO}$ and $\mathrm{CO}_{2}$ analysers are used to quantify the fire effluents, corroborated by $\mathrm{CO}$ and $\mathrm{O}_{2}$ electrochemical sensors.

A secondary oxidiser containing quartz wool at $900^{\circ} \mathrm{C}$ is used to fully oxidise a portion of the diluted fire effluent. The difference between $\mathrm{CO}_{2}$ concentrations from the effluent dilution chamber and secondary oxidizer gives a measure of the products of incomplete combustion, such as $\mathrm{CO}$, hydrocarbons etc. Oxygen concentration from 
the secondary oxidiser may also be measured to obtain $\phi$ for commercial products or other materials of unknown composition.

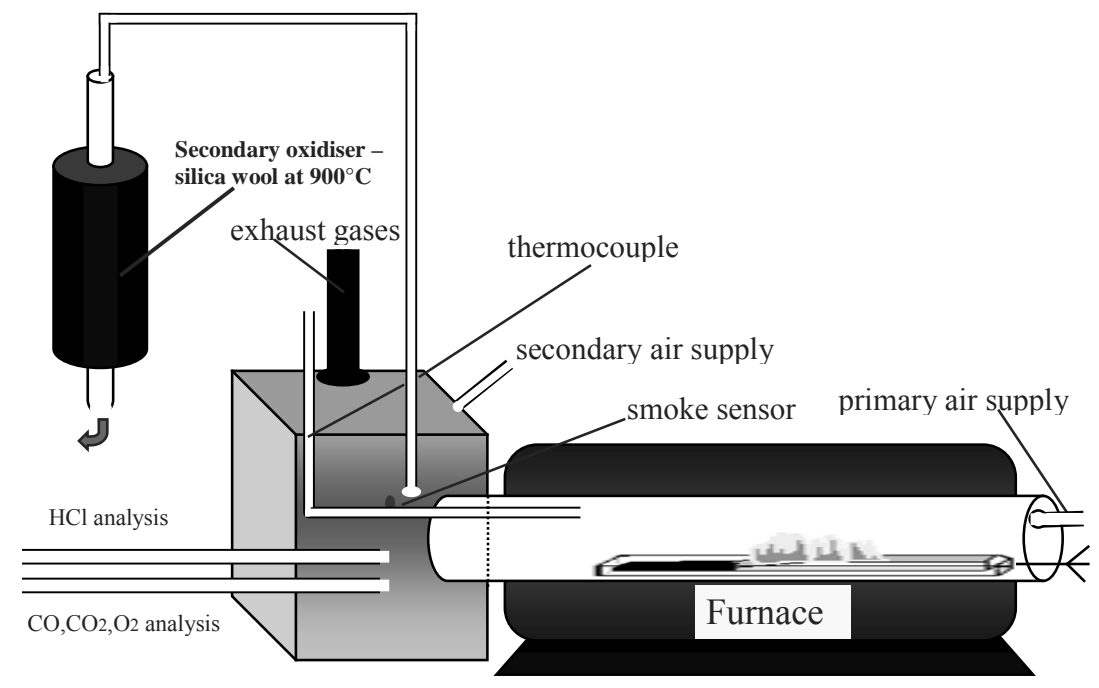

Figure 1 The Purser Furnace

\section{Experimental Characterisation}

The fire condition is dependant on the radiant flux, or temperature. Temperature profiles between the quartz furnace tube and the furnace liner were measured. Temperature profiles of the boat within the furnace tube, with and without polymer as it travels into the furnace, are reported for different fire conditions. In addition a vertical temperature profile inside the effluent dilution chamber shows the flow of effluent gases. In order to relate the steady state tube furnace measurements to different fire tests and scenarios, it is necessary to measure the radiant heat flux in the sample boat for different temperatures; this was achieved using a slug calorimeter (a small solid cylinder of copper containing a thermocouple in its centre). Radiant heat flux measurements were undertaken for 350,650 and $825^{\circ} \mathrm{C}$. The cooling effect of primary air on temperature inside the tube has been shown to be significant for higher air flows.

Experimental repeatability is important in assessing the reliability, and to estimate the uncertainty in the measurements. Replicate runs were performed to determine the repeatability using different materials and different fire scenarios. The 
ability to reproduce two fire stages for polypropylene is compared to the defined fire stages of ISO $19706 .^{11}$

\section{Temperature profiles between the furnace tube and the quartz combustion tube}

The flow of air through a cylindrical tube will either be laminar, at low velocity or turbulent, at higher velocity. If an empty cylindrical furnace tube is considered, an empirical rule predicts that only air flows greater than 1000 litres/min would flow so quickly through the tube that they give rise to a Reynolds number greater than 2300. This is the point when the flow would be expected to switch from laminar to turbulent. The air flows used in the tube furnace are much lower, not normally exceeding 25 litres $\min ^{-1}$. However, the presence of the sample boat with a vertical end occupying approximately half of the furnace tube area would be expected to disrupt the laminar air flow of the primary air as it travels over the burning sample, particularly at higher air velocities. The temperature profiles outside the furnace tube (between the furnace lining and the quartz furnace tube) were measured when the furnace was set to $700^{\circ} \mathrm{C}$ by inserting 4 thermocouples between the two tubes arranged at $90^{\circ}$ intervals, the thermocouples were inserted into the furnace $10 \mathrm{~cm}$ at a time from the outside edge of the furnace and held in each position for one minute. During insertion some rotation of the 4 thermocouples around the axis of the tube occurred, so that thermocouple labelled "right" moved towards the top etc.

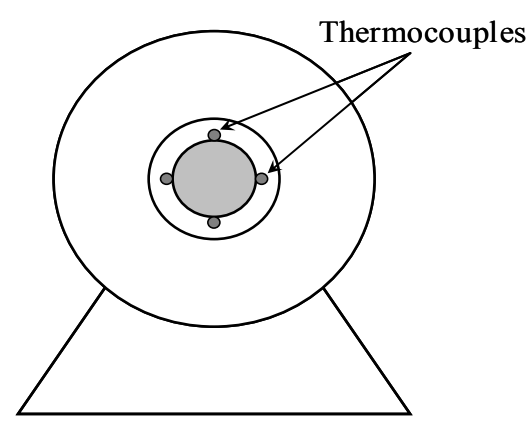

Figure 2 Positions for measurement of temperature using four thermocouples

The data presented in Figure 3 show large variations between top and bottom at the furnace mouth, reducing to an insignificant variation in the middle of the furnace. However, in normal use a glass wool plug sits between the quartz tube and the furnace liner. This was removed from the front end of the tube, but left in place at 
the far end. The differences between top and bottom are lower at the far end, where the glass wool was left in place.

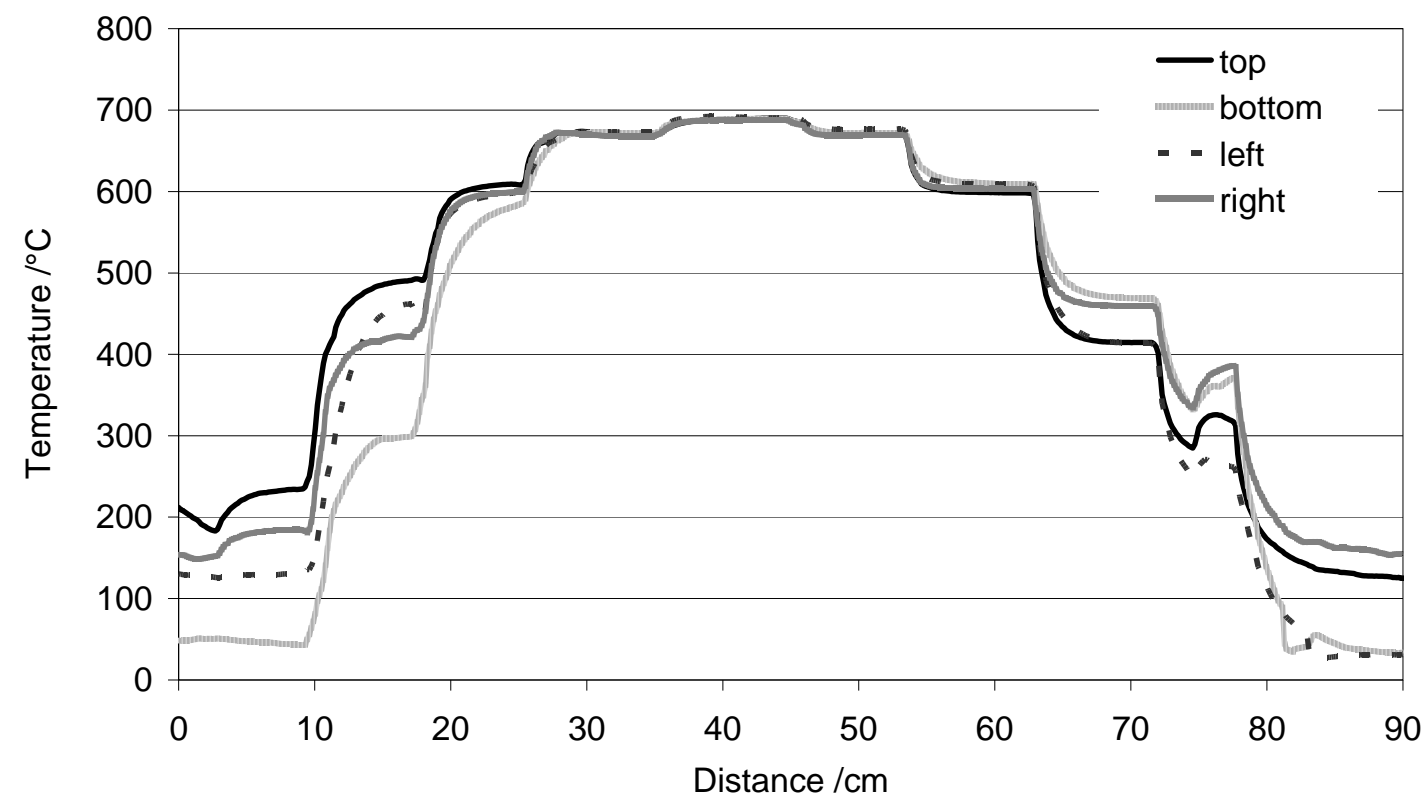

Figure 3 Temperature profiles outside the furnace tube

These data show that in the middle of the tube, the temperature is uniform around the tube, suggesting that the heat flux also has a uniform radial distribution. The temperature set on the furnace was almost reached in the centre of the tube and the temperature close to $700^{\circ} \mathrm{C}$ was observed within central $30 \mathrm{~cm}$ part of the furnace showing only small differences.

\section{Temperature Profiles in the sample boat}

The temperature profiles within the furnace tube with and without polymer were investigated. Two flaming conditions were studied, well-ventilated (air flow of $15 \mathrm{l} / \mathrm{min}$ in combustion tube) and under-ventilated (4 1/min in combustion tube) both with the furnace set to $750^{\circ} \mathrm{C}$, with a thermocouple travelling in the boat. In both cases a run was undertaken with no sample and then with a $1 \mathrm{~g} \mathrm{~min}^{-1}$ feed rate with a polypropylene (PP) sample which ignited and burnt. Temperatures were measured both in the sample boat and also in the mixing chamber. Figure 4 shows the temperature profile for each run, illustrating the variation in heating rate, with 
ventilation, with the lower air flow giving a more uniform heating rate. Except in the case of the well-ventilated run with PP, where a significant temperature rise resulted from flaming combustion, the sample temperature was significantly lower than the furnace temperature. This is addressed in the IEC, BS and ISO tube furnace standards where a procedure is described to compensate for the difference between furnace and sample temperature at different ventilation levels, but was not used in these characterisation experiments. For the PP runs, after the thermocouple passes the hottest zone of the furnace, the heat of combustion of PP manifests itself as a delay in cooling from 24 minutes to between 27 and 30 minutes.

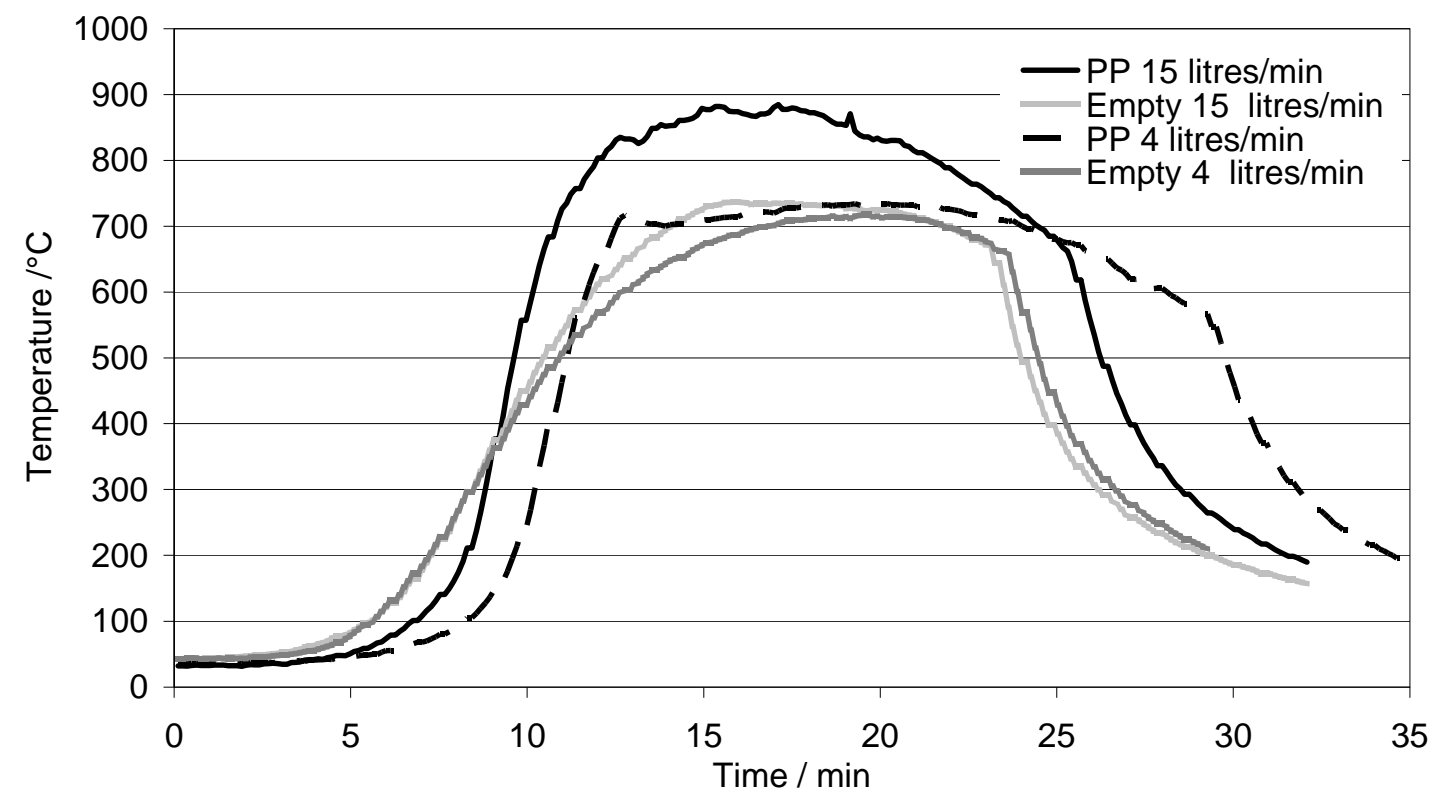

Figure 4 Temperature profiles inside the tube furnace for two fire conditions

The data shows that, at least in some cases, the sample temperature during burning is significantly higher then the furnace temperature.

\section{Temperature Profiles in the Mixing Chamber}

Thermocouples were set up inside the mixing chamber to measure the temperature variation at heights $25 \mathrm{~mm}, 75 \mathrm{~mm}, 175 \mathrm{~mm}$ and $275 \mathrm{~mm}$ from the base of the mixing chamber, in a vertical line above and below the end of the furnace tube (which protrudes $55 \mathrm{~mm}$ into the mixing chamber). A further thermocouple was inserted $30 \mathrm{~mm}$ inside the furnace tube at a height of around $85 \mathrm{~mm}$ (Figure 5). 


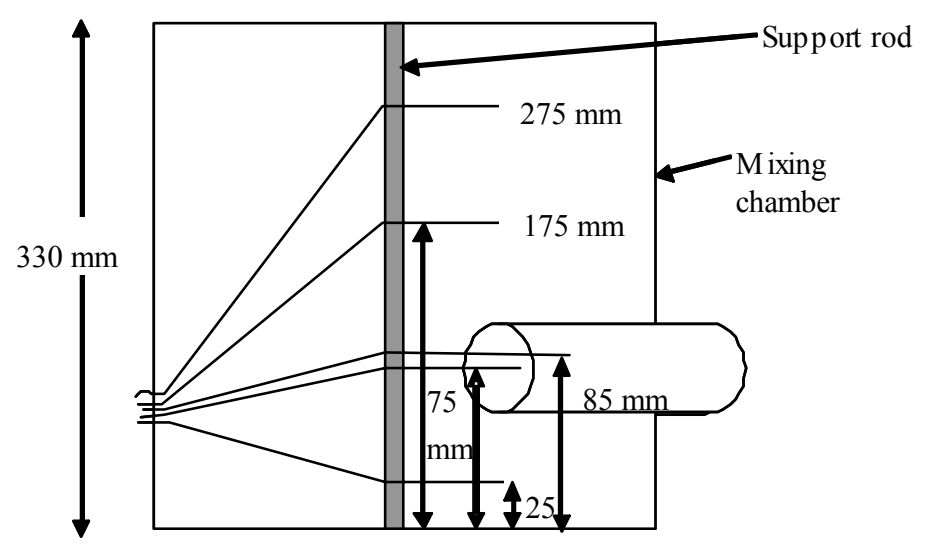

Figure 5 Positions of thermocouples inside the effluent dilution chamber

Figure 6 presents temperature measurements from the effluent dilution chamber. The furnace temperature was set to $750^{\circ} \mathrm{C}$ and primary air flow was 15 litres per minute (so the secondary air flow was 35 litres $\mathrm{min}^{-1}$ ) replicating the wellventilated condition.

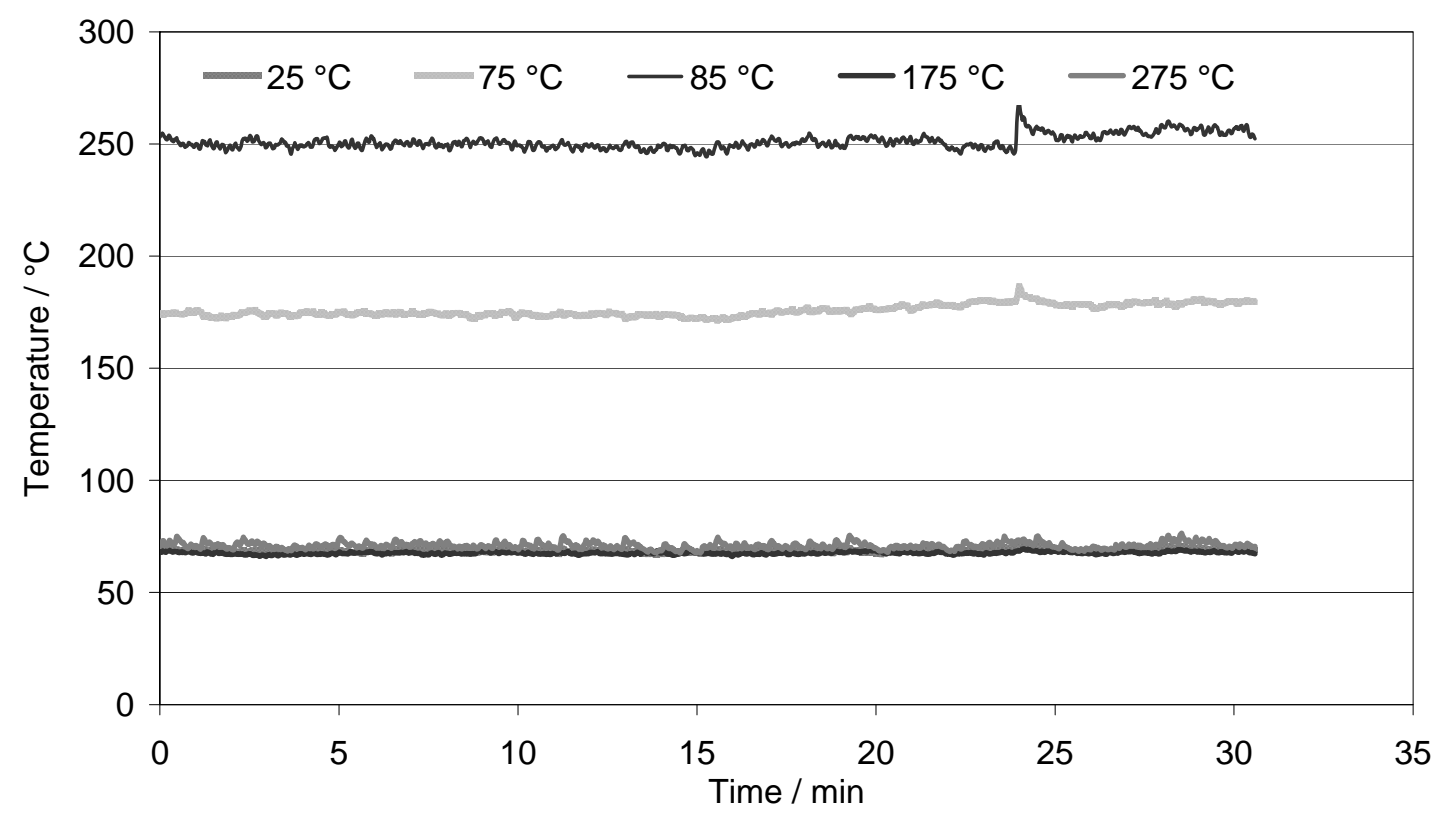

Figure 6 Temperature profiles in effluent dilution for empty boat at $750^{\circ} \mathrm{C}$ with 15 litres $\mathrm{min}^{-1}$ primary air flow

The highest recorded temperature was for thermocouple placed $30 \mathrm{~cm}$ inside the tube, at a height of $85 \mathrm{~cm}$, which reached $250^{\circ} \mathrm{C}$. The thermocouple at the mouth 
of the tube, $75 \mathrm{~mm}$ above the base of the mixing chamber recorded temperatures in range of 175 and $180^{\circ} \mathrm{C}$. The temperature at this point was expected to be lower because of mixing with secondary air. The other thermocouples all recorded very similar temperatures of around $70^{\circ} \mathrm{C}$. This shows that inside the effluent dilution chamber the temperature is uniform (apart from the zone very close to the furnace tube). This demonstrates that the mixing within the effluent dilution chamber in terms of temperature distribution is effective, within the range of secondary air flows (25-50 litres $\min ^{-1}$ ) used.

The temperature profile in the effluent dilution chamber was also measured for the under-ventilated condition, with the furnace temperature set to $750^{\circ} \mathrm{C}$ and primary air flow at 4 litres per minute (so the secondary air flow was 46 litres $\mathrm{min}^{-1}$ ) (Figure 7).

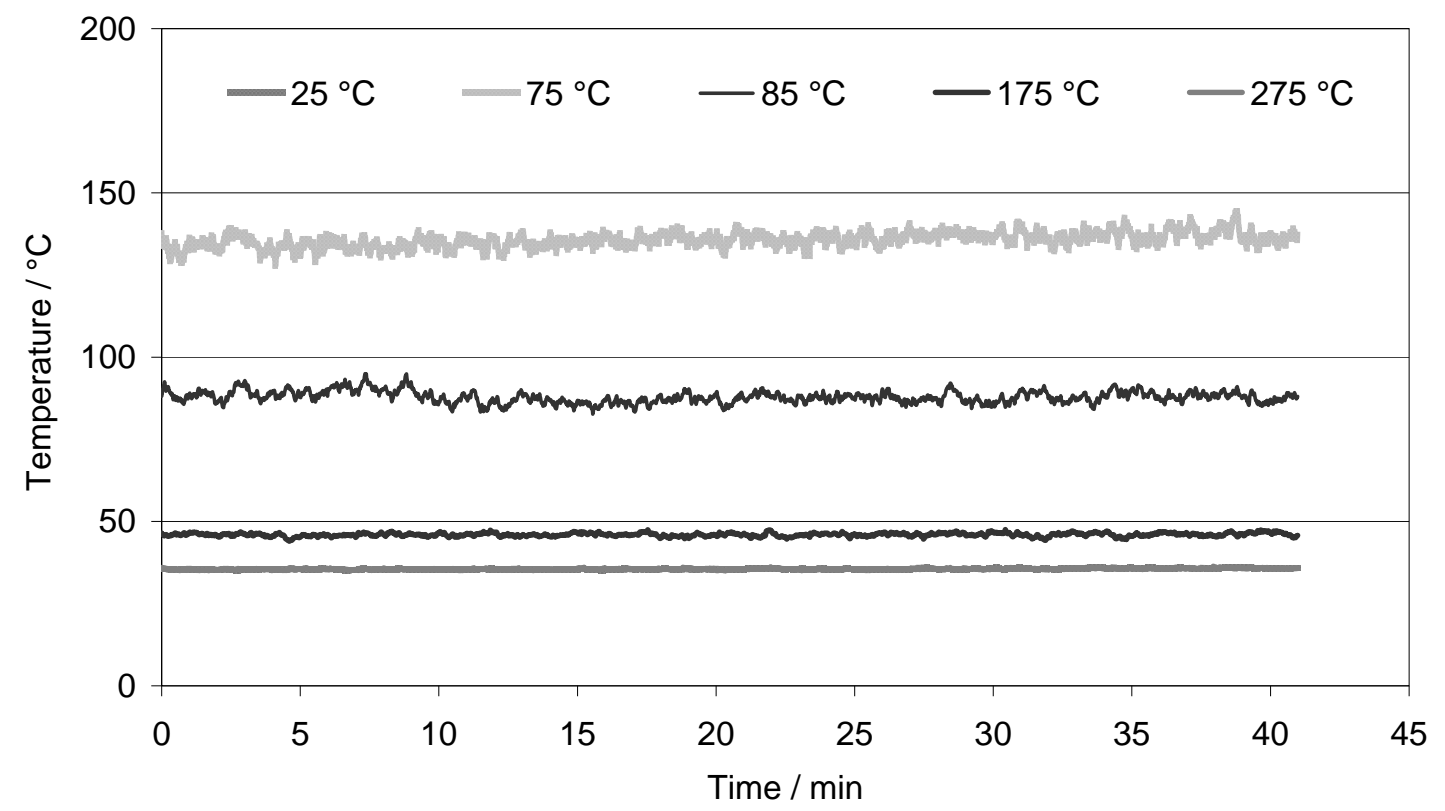

Figure 7 Temperature profiles for effluent dilution chamber for empty boat at $750^{\circ} \mathrm{C}$ with 4 litres $\mathrm{min}^{-1}$ primary air flow

The temperature at the top and bottom of the effluent dilution chamber 25 and $275 \mathrm{~mm}$ above the base was $35^{\circ} \mathrm{C}$, but $175 \mathrm{~mm}$ above the base the temperature was $46^{\circ} \mathrm{C}$, possibly because the smaller primary flow rose more directly above mouth of the furnace tube. Surprisingly, the temperature $\left(90^{\circ} \mathrm{C}\right) 3 \mathrm{~cm}$ inside the tube $(85 \mathrm{~mm})$ 
was lower then the temperature $\left(135^{\circ} \mathrm{C}\right)$ at the mouth of the tube $(75 \mathrm{~mm})$. This may be due to stratified air flow with a cooler layer very close to the top, and the hottest gas nearer to the axis of the tube.

\section{Adjustment of a furnace temperature to match conditions in tube}

The furnace temperature setting will not generally be equal to the temperature in the middle of the quartz tube, because of the cooling effect of the primary air. To compensate for this, the set temperature of the furnace needs to be increased by a fixed amount for a particular temperature and air flow.

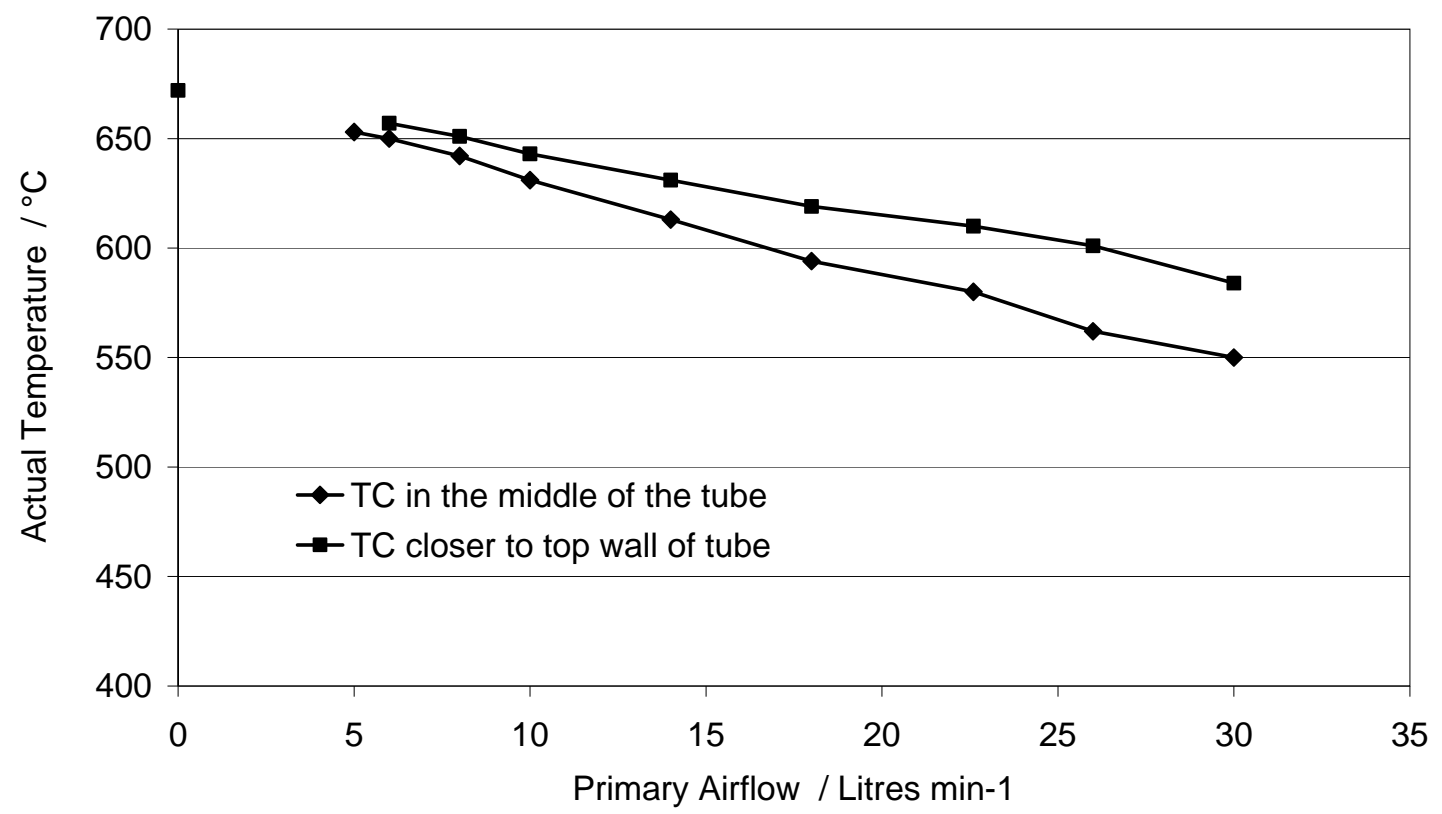

Figure 8 Actual temperature inside the tube furnace for different air flows

Figure 8 presents the data obtained when the temperature on the control panel of the furnace was set to $650^{\circ} \mathrm{C}$. The air passed through the tube and a cooling effect was observed. The higher the air flow, the greater the cooling effect. Two sets of data are presented. One where the thermocouple was situated very close to the top of the wall of the tube, and the other where it was in the centre of the furnace tube, as described in ISO 19700. As expected, the higher temperature was observed close to the wall, and lower for the centre of the tube.

The highest cooling effect was observed for a very high air flow of $30 \mathrm{l} / \mathrm{min}$ where the temperature fell from $650^{\circ} \mathrm{C}$ to $550^{\circ} \mathrm{C}$, which could result in a significant difference in terms of fire conditions. These data illustrate the importance of 
compensating for this cooling effect from primary airflow, and demonstrate the need to find the furnace temperature setting required to reach 350,650 and $825^{\circ} \mathrm{C}$ inside the furnace. These data are for illustration purposes only, the specific geometry and tube dimensions will change the actual adjustment required.

\begin{tabular}{|c|c|c|c|c|c|c|c|c|}
\hline \multirow{3}{*}{$\begin{array}{c}\text { Furnace } \\
\text { Actual } \\
\text { Temperature } \\
I^{\circ} \mathrm{C}\end{array}$} & \multicolumn{8}{|c|}{ Air Flow / L min ${ }^{-1}$} \\
\hline & 2.0 & 2.7 & 8 & 10 & 18 & 22.6 & 25 & 30 \\
\hline & \multicolumn{8}{|c|}{ Furnace temperature settings $I^{\circ} \mathrm{C}$} \\
\hline 350 & 355 & & & & & & & \\
\hline 650 & & & 657 & 665 & 684 & 692 & 709 & 735 \\
\hline 825 & 832 & 827 & & & & & & \\
\hline
\end{tabular}

Table 1 Furnace temperatures settings to reach $350,650,825^{\circ} \mathrm{C}$ for different air flows

Table 1 shows the temperatures settings required to meet the fire conditions. These corrections are particularly for the well-ventilated flaming conditions such as that defined in IEC 60695-7-50, where the primary air flow is $22.61 / \mathrm{min}$.

\section{Mixing inside the effluent dilution chamber}

Some preliminary temperature measurements were taken at the end of the tube furnace in order to find the best location for sampling of easily adsorbed analytes such as $\mathrm{HCl}$, both within the mixing chamber, and in the furnace tube. The thermocouple was inserted into the furnace tube through the mixing chamber and temperature data were recorded in three positions, at the top, in the centre and at the bottom of the tube, shown in Figure 9. 


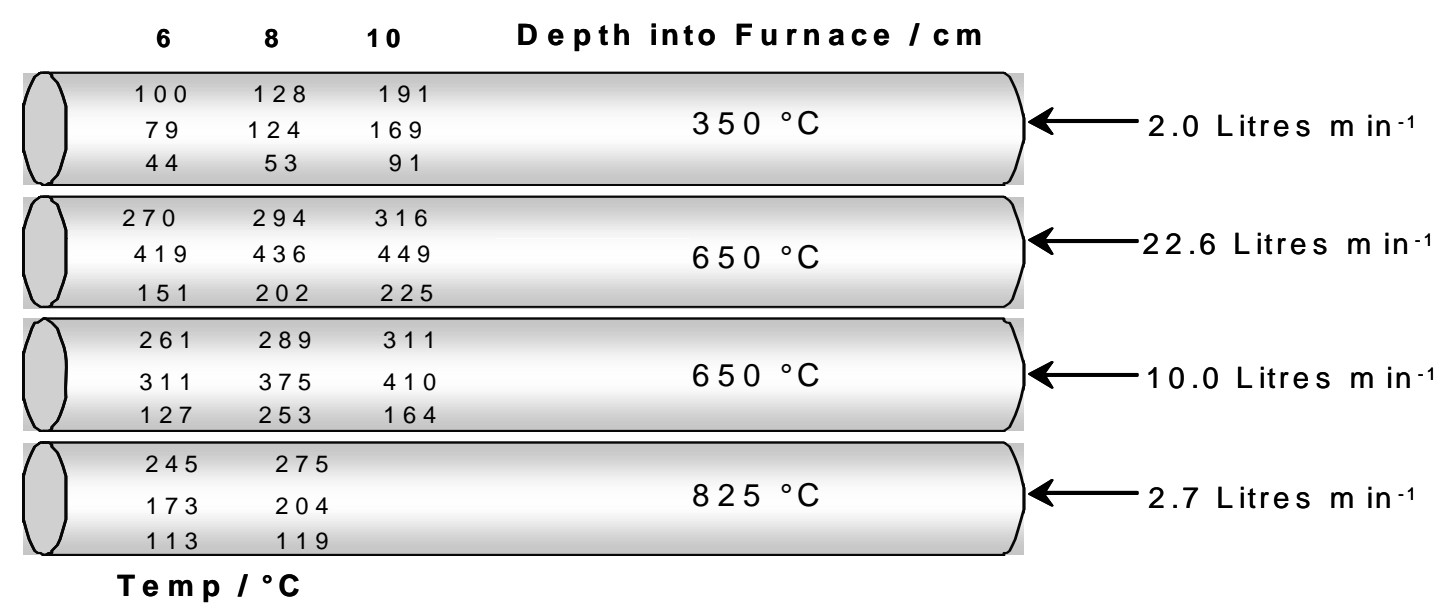

Figure 9 Temperature measurements inside the tube of Purser furnace

This shows significant temperature differences between bottom, centre and top of the tube. The mixing inside the tube is poor showing stratification, with the hottest layer at the top at lower air flows, and mixing with the hottest gases in the middle at higher air flows. This illustrates the problems of direct sampling from the furnace tube.

In contrast, the temperature measurements in the mixing chamber suggest that complete mixing occurs within a short distance of the effluent leaving the furnace tube. To confirm adequate mixing inside the effluent dilution chamber, and to ensure a suitable location for $\mathrm{HCl}$ sampling, $\mathrm{HCl}$ concentrations from decomposition and burning of a commercial sample of rigid PVC were measured near the top and bottom of the chamber.

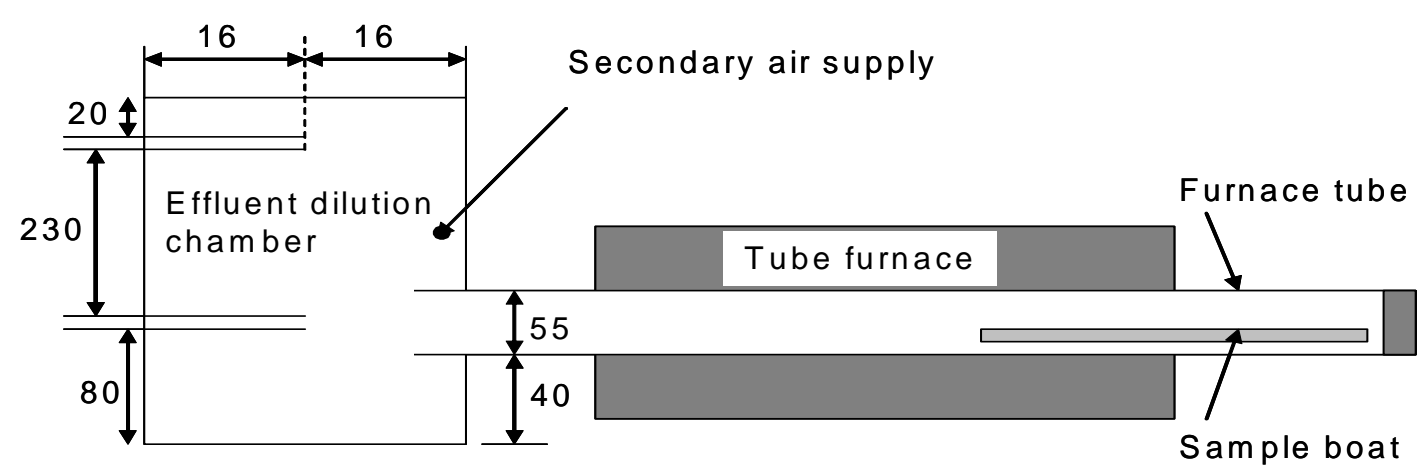

Figure 10 Comparison of sampling locations for $\mathrm{HCl}$ on top and bottom of effluent dilution chamber 
Figure 10 shows the sampling locations. The data ${ }^{12}$ in Table 2 shows that the concentrations in different parts of the effluent dilution chamber are the same because the results obtained (for both sampling lines) were the same. This confirms efficient mixing within the effluent dilution chamber.

\begin{tabular}{|l|c|c|c|}
\hline Sampling point & $\begin{array}{c}\text { Temp } \\
/{ }^{\circ} \mathbf{C}\end{array}$ & $\begin{array}{c}\text { Primary air flow / } \\
\text { L } \text { min }^{-1}\end{array}$ & $\begin{array}{c}\text { Yield of HCl / } \\
\text { \% }\end{array}$ \\
\hline $\begin{array}{l}\text { Sample taken from top of effluent dilution } \\
\text { chamber }\end{array}$ & 350 & 2.0 & 36.5 \\
\hline $\begin{array}{l}\text { Sample taken from bottom of effluent } \\
\text { dilution chamber }\end{array}$ & 350 & 2.0 & 36.5 \\
\hline $\begin{array}{l}\text { Sample taken from top of effluent dilution } \\
\text { chamber }\end{array}$ & 825 & 2.7 & 48.1 \\
\hline $\begin{array}{l}\text { Sample taken from bottom of effluent } \\
\text { dilution chamber }\end{array}$ & 825 & 2.7 & 48.1 \\
\hline
\end{tabular}

Table 2 Results obtained for samples taken from bottom and top of effluent dilution

$$
\text { chamber }^{12}
$$

In addition, during a well-ventilated run $\left(\mathrm{T}=650^{\circ} \mathrm{C}, \phi=0.75\right.$, primary air flow $=13.21 / \mathrm{min}$ ) with nylon 6.6 a numeric grid was fixed to the back of the effluent dilution chamber, and the smoke obscuration recorded on video. The video of the effluent dilution chamber was recorded and some still images are presented with the time shown from the start of the run. The laser beam for smoke detection is visible across the centre of each image. 
Ignition occurred at 6 minutes $58 \mathrm{~s}$

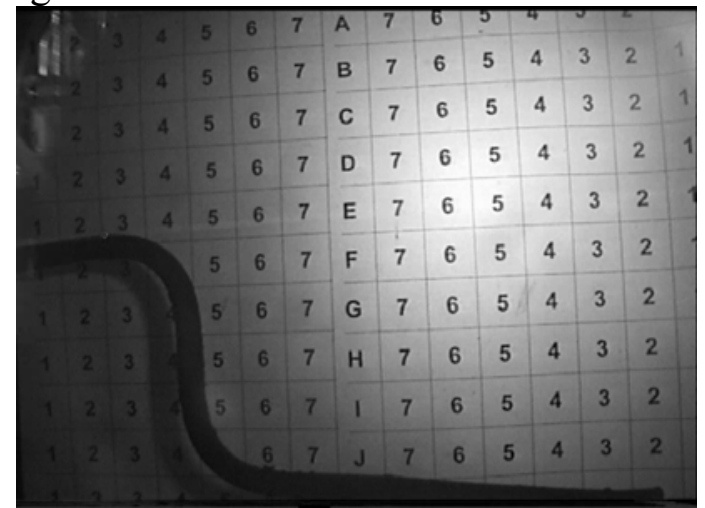

Time 7:08

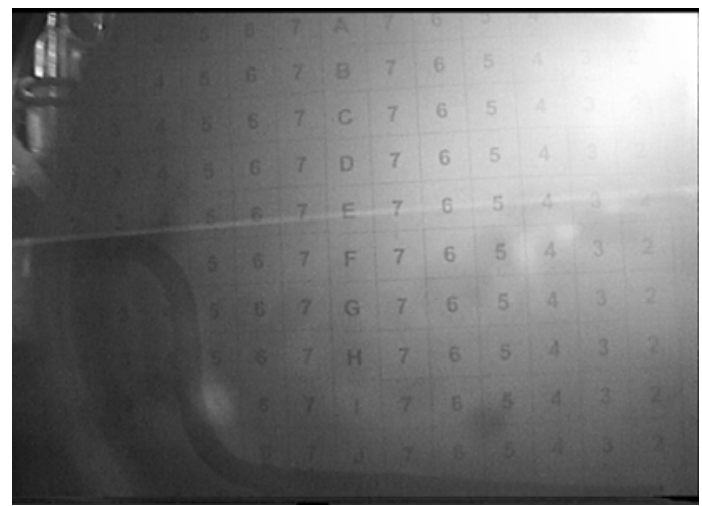

Time 7:15

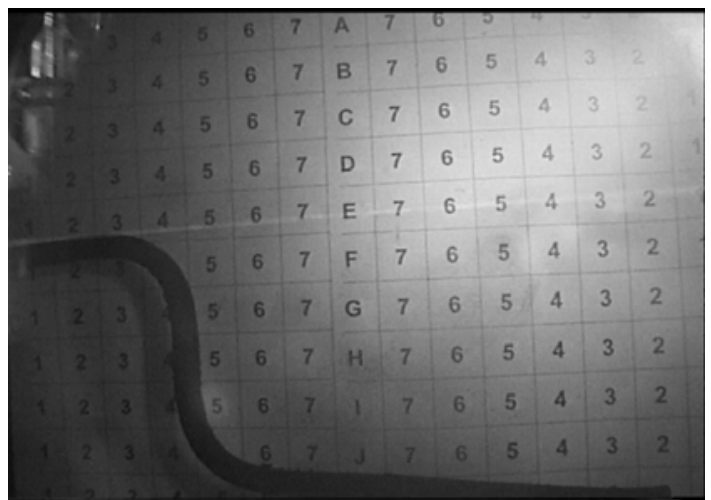

Time $7: 11$

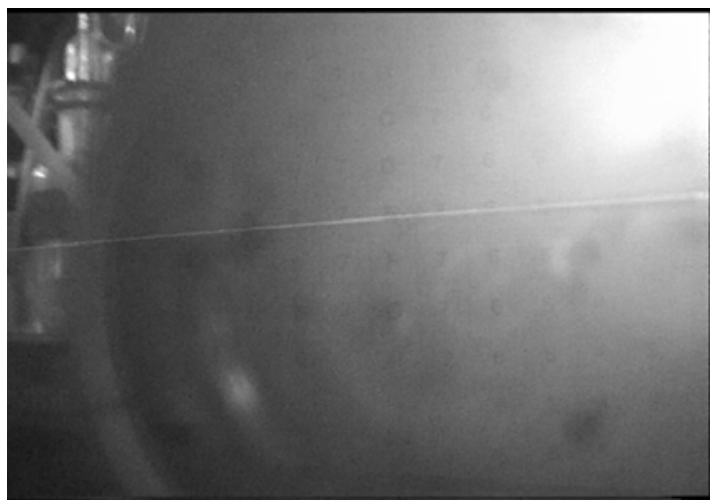

Time 7:20

Photo 1 The mixing inside the effluent dilution chamber

\section{Radiant Flux Measurements}

In order to relate the steady state tube furnace measurements to different fire tests and scenarios, the radiant heat flux in the sample boat was measured for different temperatures using a slug calorimeter. The methodology used to measure the heat flux was described by Lyon $^{13}$ and the measurements were undertaken for 350, 650 and $825^{\circ} \mathrm{C}$. Measurements were conducted by attaching the slug calorimeter to the sample positioning rod and quickly inserting the slug to the tube furnace. The slug was supported in the centre of the furnace tube, above the boat, and away from its support. Since ignition is known to occur in the steady state tube furnace before the sample reaches the hottest central area, the slug was inserted at different depths to determine the radiant heat flux in each part of the tube furnace. The temperature measurements at $825^{\circ} \mathrm{C}$ are shown on Figure 11 . The same procedures were repeated for 350 and $650^{\circ} \mathrm{C}$. 


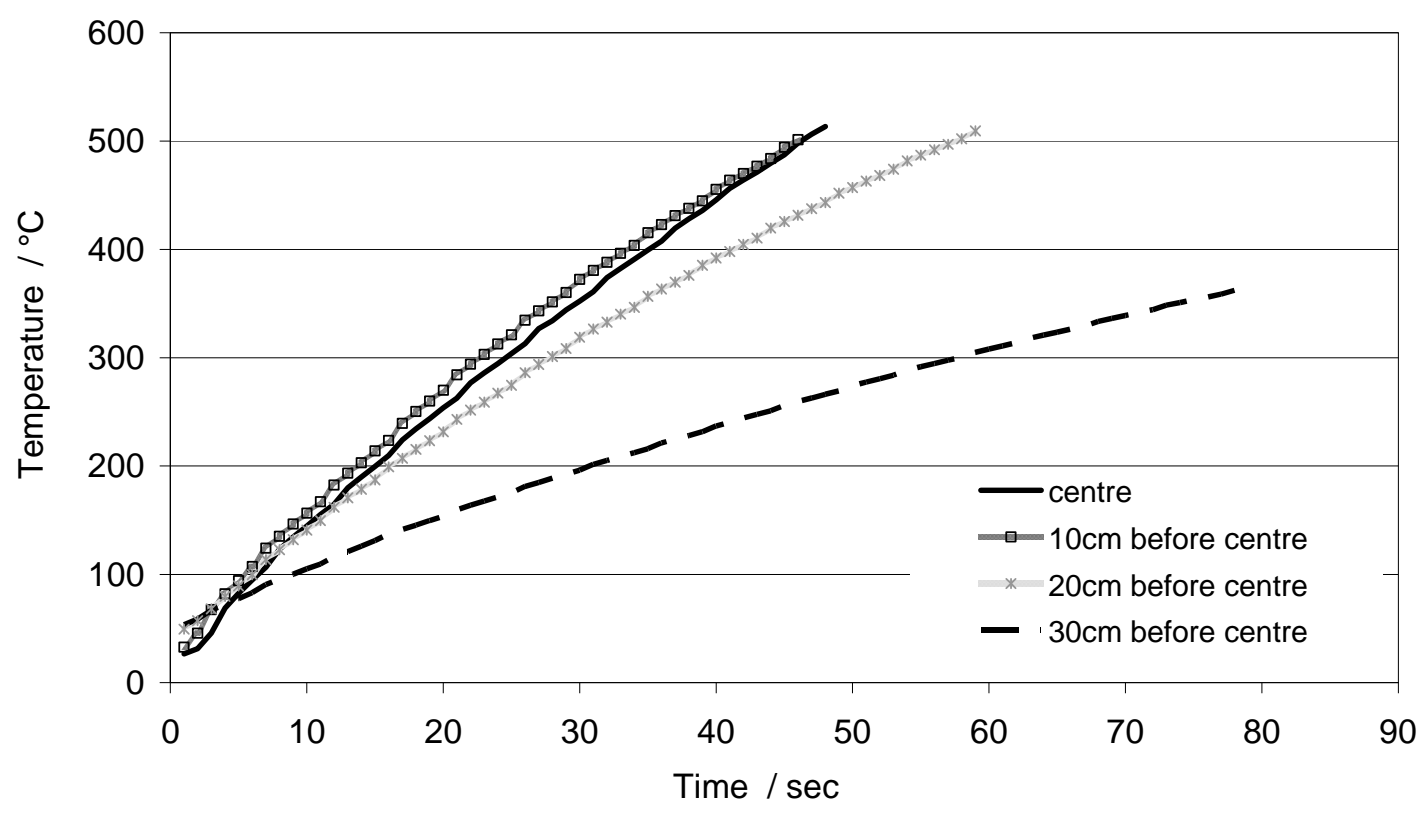

Figure 11 Increase of slug temperature inside the tube furnace set to $825^{\circ} \mathrm{C}$

The radiant heat flux was determined from the initial heating rate, before its own radiative heat losses became significant. This was obtained as a least squares fit of the initially-linear heating curve of which two are shown on Figure 11.

The well-established relationship to radiant flux (q) as presented by Lyon ${ }^{13}$ is shown in Equation 2.

$$
q=\frac{m c}{\alpha A}\left(\frac{d T}{d t}\right)_{t \rightarrow 0} \quad \text { Equation 2 }
$$

where:

$\left(\frac{d T}{d t}\right)_{t \rightarrow o}$ - is the initial slope of the temperature curve

$\mathrm{m}$ - is the mass of the slug

$\mathrm{c}-$ is the heat capacity of the slug material

$\alpha$ - is the emissivity of surface oxidised copper, gives as $0.6-0.7$ (taken from CRC Handbook of Chemistry and Physics) ${ }^{14}$. A value of 0.65 was used.

A - is the surface area of the slug. The area of the slug sides were used, since little radiant flux would impinge on the ends. 


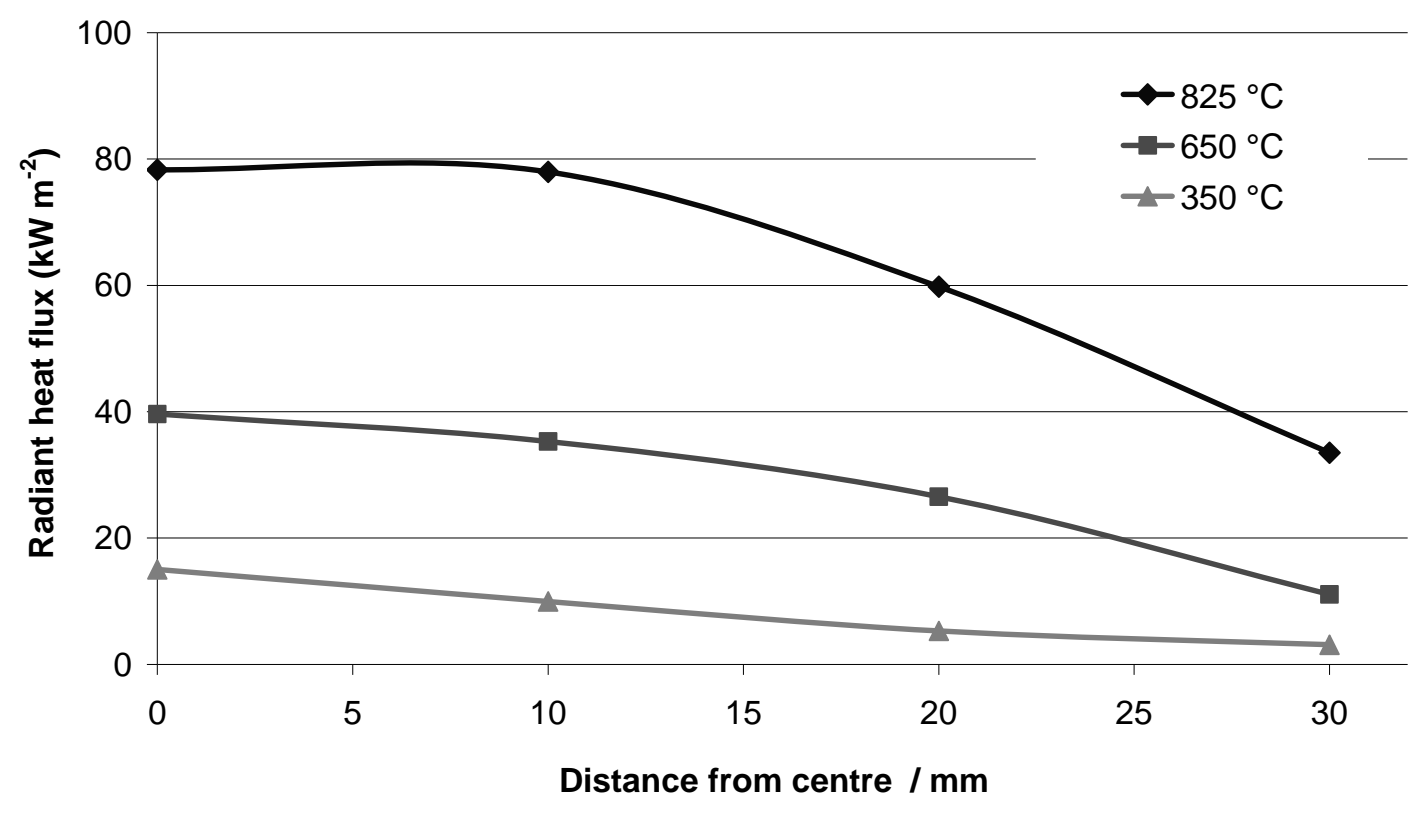

Figure 12 Radiant Heat Flux for different furnace temperatures settings

Figure 12 shows radiant heat fluxes for different furnace set temperatures and different parts of the furnace. The highest radiant heat flux was observed for a temperature of $825^{\circ} \mathrm{C}$ in the centre of the tube and reached $78 \mathrm{~kW} \mathrm{~m}^{-2}$, but $30 \mathrm{~cm}$ from the centre the radiant heat flux was only $33 \mathrm{~kW} \mathrm{~m}^{-2}$. This lower value may be sufficient to ignite typical non-fire retarded organic polymers. For a furnace temperature of $650^{\circ} \mathrm{C}$ the heat flux in the centre of the tube was $39 \mathrm{~kW} \mathrm{~m}^{-2}$ and at $350^{\circ} \mathrm{C}$ it was $15 \mathrm{~kW} \mathrm{~m}^{-2}$. A large body of literature exists on the measurement of radiant flux in fires, and it is acknowledged that there may be significant errors in this data. It is reported here to show that such measurements can be undertaken, and to give indicative values of the applied heat flux under different conditions. This data allows the Purser furnace results at different fire conditions to be correlated with other techniques for replicating fires.

\section{Repeatability of tube furnace}

Repeatability is the most basic criteria which must be satisfied for any measurement technique. The repeatability can be quantified as an estimate of the uncertainty in the measurements from the scatter of the experimental results. In the steady state tube furnace, the results show random variation both during the steady 
state period of a run, and between runs. Both variations are reported here. Five replicate runs were performed to determine the repeatability using polypropylene in two ventilation conditions at $650^{\circ} \mathrm{C}$, as described in ISO TS 19700 .

\begin{tabular}{|l|c|c|c|c|c|}
\hline Sample & $\begin{array}{c}\mathbf{O}_{2} \\
\mathbf{\%}\end{array}$ & $\begin{array}{c}\mathbf{C O}_{2} \\
\mathbf{\%}\end{array}$ & $\begin{array}{c}\text { Secondary } \\
\mathbf{C O}_{2} \\
\mathbf{\%}\end{array}$ & $\begin{array}{c}\mathbf{C O} \\
\mathbf{p p m}\end{array}$ & $\begin{array}{c}\text { Smoke } \\
\text { Optical } \\
\text { Density }\end{array}$ \\
\hline $\mathrm{A}$ & $16.3 \pm 0.19$ & $3.03 \pm 0.12$ & $3.59 \pm 0.23$ & $712 \pm 200$ & $0.33 \pm 0.05$ \\
\hline $\mathrm{B}$ & $16.4 \pm 0.14$ & - & $3.51 \pm 0.09$ & $806 \pm 96$ & $0.27 \pm 0.07$ \\
\hline $\mathrm{C}$ & $16.7 \pm 0.12$ & $2.77 \pm 0.08$ & $3.41 \pm 0.16$ & $811 \pm 337$ & $0.31 \pm 0.05$ \\
\hline $\mathrm{D}$ & $16.1 \pm 0.20$ & $3.14 \pm 0.10$ & $3.90 \pm 0.21$ & $918 \pm 371$ & $0.26 \pm 0.03$ \\
\hline E & $16.4 \pm 0.17$ & $3.03 \pm 0.11$ & $3.58 \pm 0.17$ & $604 \pm 177$ & $0.31 \pm 0.06$ \\
\hline average & $16.4 \pm 0.21$ & $2.99 \pm 0.16$ & $3.60 \pm 0.18$ & $770 \pm 118$ & $0.30 \pm 0.03$ \\
\hline
\end{tabular}

Table 3 Variations of concentrations for five runs for PP at $\phi=0.75$

Table 3 and 4 present differences with the steady state period of each run. An estimate of the experimental error, calculated as the standard deviation (which may be loosely explained as the value within which $\frac{2}{3}$ of the results would be expected to fall) is also shown. For samples A to $\mathrm{E}$ this was calculated from around 40 data points within the 5 minute steady state. The final average value takes the standard deviation of the five data points and the error is the standard deviation within the five points. This shows that there is a similar random fluctuation within each run, and between the individual runs. The random error was greatest for $\mathrm{CO}$ concentrations and for the smoke, because of their lower absolute values and also perhaps because of the much greater sensitivity of $\mathrm{CO}$ yield and smoke to fire conditions (caused by the oscillations within the "steady state during each run).

\begin{tabular}{|l|c|c|c|c|c|}
\hline \multicolumn{1}{|c|}{ Sample } & $\begin{array}{c}\mathbf{O}_{2} \\
\mathbf{\%}\end{array}$ & $\begin{array}{c}\mathbf{C O}_{\mathbf{2}} \\
\mathbf{\%}\end{array}$ & $\begin{array}{c}\text { Secondary } \\
\mathbf{C O}_{\mathbf{2}} \\
\mathbf{\%}\end{array}$ & $\begin{array}{c}\mathbf{C O} \\
\mathbf{p p m}\end{array}$ & $\begin{array}{c}\text { Smoke } \\
\text { Optical } \\
\text { Density }\end{array}$ \\
\hline $\mathrm{A}$ & $18.8 \pm 0.03$ & $2.89 \pm 0.10$ & $3.36 \pm 0.37$ & $4052 \pm 265$ & $0.73 \pm 0.21$ \\
\hline $\mathrm{B}$ & $18.7 \pm 0.04$ & $3.57 \pm 0.09$ & $3.14 \pm 0.58$ & $3373 \pm 251$ & $0.75 \pm 0.11$ \\
\hline $\mathrm{C}$ & $18.6 \pm 0.02$ & $3.76 \pm 0.11$ & $3.39 \pm 0.14$ & $4826 \pm 510$ & $0.72 \pm 0.19$ \\
\hline $\mathrm{D}$ & $18.6 \pm 0.02$ & $3.72 \pm 0.11$ & $3.35 \pm 0.20$ & $4395 \pm 337$ & $0.58 \pm 0.12$ \\
\hline E & $18.7 \pm 0.05$ & $3.49 \pm 0.07$ & $2.82 \pm 0.32$ & $4301 \pm 298$ & $0.79 \pm 0.06$ \\
\hline average & $18.7 \pm 0.08$ & $3.48 \pm 0.35$ & $3.21 \pm 0.24$ & $4189 \pm 535$ & $0.71 \pm 0.08$ \\
\hline
\end{tabular}

Table 4 Variations of concentrations for five runs for PP at $\phi=2.0$ 
For the under-ventilated fire scenario, Table 4, the differences observed between runs are larger, as may be expected from the relative instability of under-ventilated burning, but are not significantly larger then the differences within the runs. For CO the absolute values of the errors from the individual runs are larger than for the wellventilated runs, but the relative error is slightly smaller (15\% for well-ventilated, $13 \%$ for under-ventilated).

Four runs were also undertaken using an PVC insulated cable. The tested cable met the Spanish NO7V-K specification, and was supplied by EuropaCable and has been described elsewhere. ${ }^{15}$ The under-ventilated fire scenario was set up according to IEC $60695-7-50$, where the furnace temperature was $825^{\circ} \mathrm{C}$.

\begin{tabular}{|l|c|c|c|c|c|}
\hline \multicolumn{1}{|c|}{ Sample } & $\begin{array}{c}\mathbf{O}_{2} \\
\mathbf{\%}\end{array}$ & $\begin{array}{c}\mathbf{C O}_{2} \\
\mathbf{\%}\end{array}$ & $\begin{array}{c}\text { Secondary } \\
\mathbf{C O}_{2} \\
\mathbf{\%}\end{array}$ & $\begin{array}{c}\mathbf{C O} \\
\mathbf{p p m}\end{array}$ & $\begin{array}{c}\text { Smoke } \\
\text { Optical } \\
\text { Density }\end{array}$ \\
\hline $\mathrm{A}$ & $20.0 \pm 0.03$ & $0.62 \pm 0.02$ & $1.14 \pm 0.04$ & $3275 \pm 386$ & $0.40 \pm 0.10$ \\
\hline $\mathrm{B}$ & $20.0 \pm 0.03$ & $0.65 \pm 0.01$ & $1.16 \pm 0.01$ & $3213 \pm 197$ & $0.47 \pm 0.11$ \\
\hline $\mathrm{C}$ & $20.0 \pm 0.03$ & $0.69 \pm 0.01$ & $1.08 \pm 0.05$ & $3100 \pm 216$ & $0.65 \pm 0.12$ \\
\hline $\mathrm{D}$ & $20.0 \pm 0.03$ & $0.68 \pm 0.02$ & $1.02 \pm 0.10$ & $3089 \pm 206$ & $0.75 \pm 0.07$ \\
\hline average & $20.0 \pm 0.03$ & $0.64 \pm 0.05$ & $1.15 \pm 0.12$ & $3312 \pm 295$ & $0.50 \pm 0.17$ \\
\hline
\end{tabular}

Table 5 Variations of concentrations for four runs for cable

Table 5 presents variations of product concentration for PVC insulated a single wire conductor for the under-ventilated fire condition. This shows a lower random error than the PP runs perhaps because of the different burning characteristics of the cable.

\section{Reproducibility of tube furnace}

An initial investigation of the interlaboratory reproducibility of the tube furnace was undertaken for a comparison between data obtained at University of Bolton and BRE (Fire and Security), formerly the UK's Fire Research Station. The series of tests were performed using commercial nylon 6.6 supplied by Invista to investigate the interlaboratory reproducibility. For all runs a temperature of $650^{\circ} \mathrm{C}$ was used and the ventilation was changed to vary the equivalence ratio. 


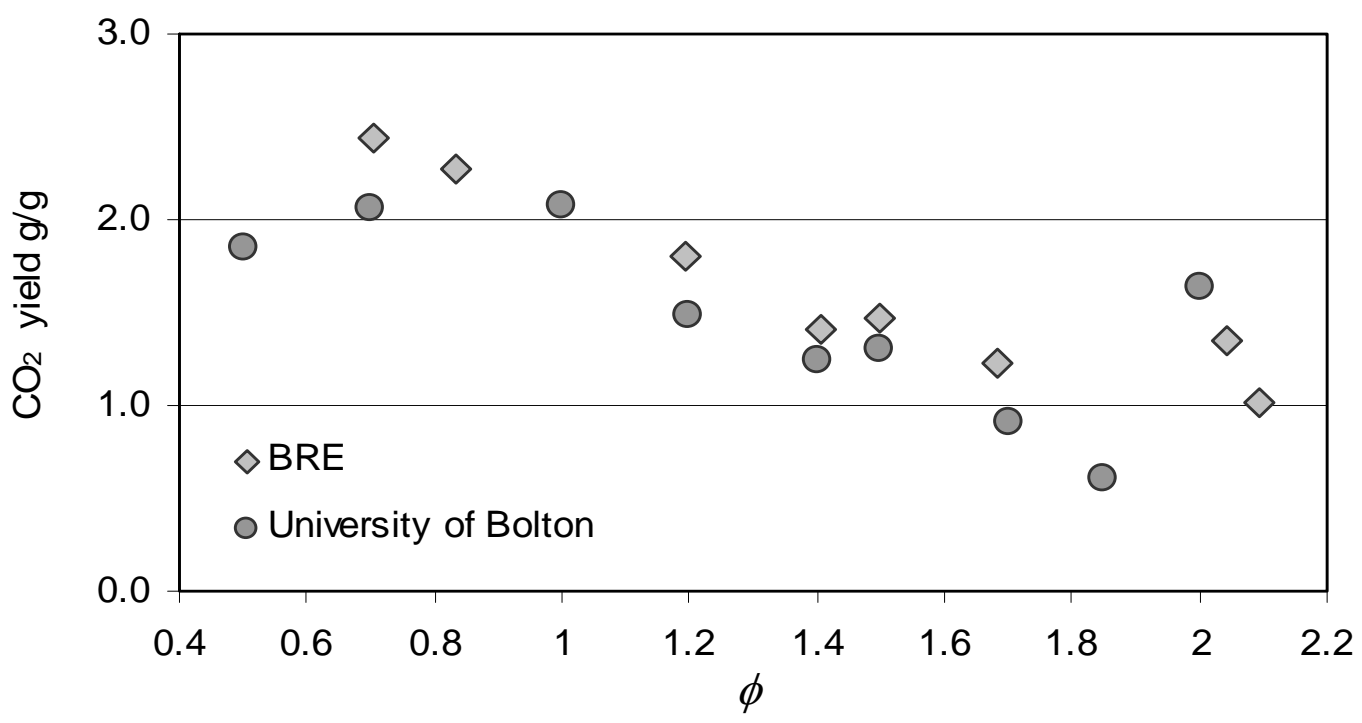

Figure $13 \mathrm{CO}_{2}$ yields for nylon 6.6 obtained in two laboratories

Figure 13 shows the relationship between the $\mathrm{CO}_{2}$ yield and the fire condition. Both sets of data show the same trend and only small differences are observed. Some data were obtained below $\phi=0.5$, which showed greater variation because of the quenching effects of high air flows, hence very unsteady flaming was observed. These data have not been reported here.

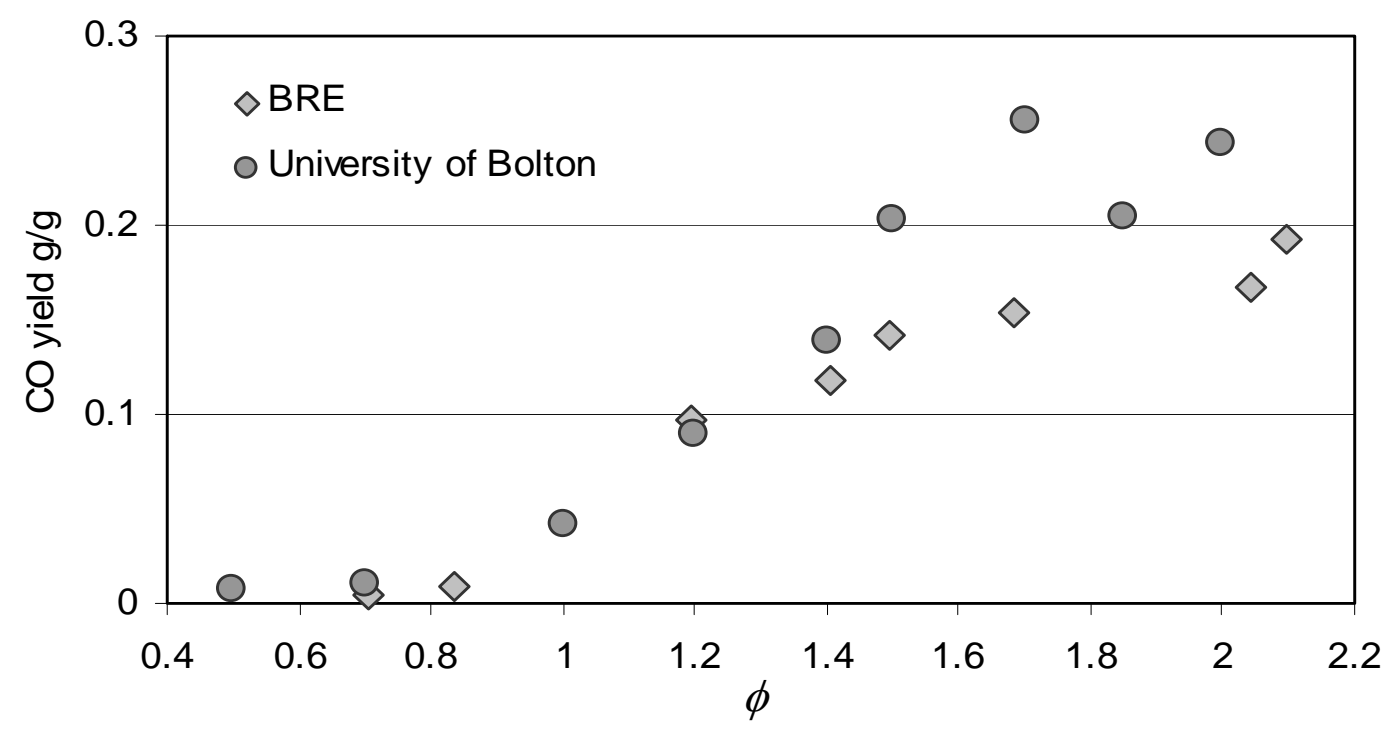

Figure 14 CO yields for nylon 6.6 obtained in two laboratories 
Figure 14 shows the variation in $\mathrm{CO}$ yield as a function of equivalence ratio for nylon 6.6 at the two laboratories. $\mathrm{CO}$ was selected because of its sensitivity to fire condition, and its importance in fire toxicity. Again, the results indicate some small differences between laboratories, but the trend remains very similar.

Initial results obtained at University of Bolton and BRE (Fire and Security) show good reproducibility, but further investigation related to reproducibility is needed in order to properly assess uncertainty in the measurements.

\section{Conclusions}

The steady state tube furnace has been recognised both as a standard method for replicating the toxic product generation of large scale fires at each of the fire stages, and as a research tool capable of providing toxic product yield data as a function of material, temperature and ventilation condition (characterised by either equivalence ratio, $\phi$, or $\mathrm{CO}_{2} / \mathrm{CO}$ ratio). The apparatus may be built from standard items of laboratory equipment, to meet the specifications in the relevant standards. Although some of the characteristics (such as temperature variation along the tube furnace) are defined by the standard, many others are only implied by it. This work describes the physical characterisation, particularly describing temperature profiles inside and outside the furnace tube, under different ventilation conditions. This gives an understanding of gas movement in the furnace tube, and also in the mixing chamber. The main conclusions from this part of the work are:

- The pre-set furnace temperature may be significantly lower than the sample temperature, particularly for the well-ventilated condition with high primary air flow, hence it is essential to apply the temperature corrections described in the standards. During well-ventilated combustion, the temperature may be significantly higher than the corrected temperature.

- The gas flow in the furnace tube may be laminar, resulting in stratification with poor mixing in the furnace tube, particularly at lower primary air flows.

- The temperatures around the outside of the central position of the furnace tube are radially and laterally uniform.

- The gas flows in the effluent dilution chamber lead to very efficient mixing, thus this is the ideal place to collect samples. 
The second part of the paper reports the random errors inherent in the steady state tube furnace measurements, and makes an initial attempt to assess interlaboratory reproducibility. The relatively small random fluctuation demonstrates the efficacy of the steady state approach for physical modelling toxic gas production yields, while the good interlaboratory reproducibility suggests its suitability for routine measurements of fire gas toxicity for regulatory and fire safety engineering applications. These initial findings are the subject of a formal quantification exercise though ISO's Fire Threat to People and the Environment Technical Committee, TC92 SC3, where a "round robin" interlaboratory reproducibility assessment is currently (August 2007) underway.

1 Fire Statistics United Kingdom 2004, (2006) Office of The Deputy of Prime Minister, London

2 D A Purser, The Performance of Fire Retardants in Relation to Toxicity, Toxic Hazard and Risk in Fires, Chapter 12 in Fire Retardant Materials, Edited By A R Horrocks and D Price, CRC Press/ Woodhead Publishing, Cambridge, UK, 2001.

3 BS 7990:2003 Tube Furnace method for the determination of toxic product yields in fire effluents

4 ISO TS 19700:2006 Controlled equivalence ratio method for the determination of hazardous components of fire effluents

5 W. M. Pitts, Progress in Energy and Combustion Science, Vol. 21, pp.197-237, 1995

6 J. M. Carman, D. A. Purser, T. R. Hull, D. Price, G. J. Milnes, Polymer International, Vol. 49, pp.1256-1258, 2000

7 D. A. Purser, P.J. Fardell, J. Rowley, S. Vollam and B. Bridgeman, Flame Retardants'94 Conference, London, UK. January 1994. Proceedings, pp.263-274. Interscience Communications, London

8 T.R. Hull and K.T.Paul, Fire Safety Journal, Vol. 42, pp.340-365, 2007

9 T. R. Hull, D. Price, Y. Liu, C. L. Wills, J.Brady, Polymer Degradation and Stability, Vol. 82, pp. 365-371, 2003

10 IEC 60695-7-50:2002 Fire hazard testing - Toxicity of fire effluent - Estimation of toxic potency - Apparatus and test method. International Electrotechnics Commission, Geneva

11 ISO 19706:2007 Guidelines for assessing the fire threat to people

12 K. Lebek, T. R. Hull and D. Price, Products of burning rigid PVC burning under different fire conditions, Fire and Polymers: Materials and Concepts for Hazard Prevention, ACS Symposium Series No.922, p334-347, Oxford University Press, (2005).

13 R. Filipczak, R. E. Lyon, Fire Safety Journal, Vol. 37, pp.591-604, 2002

14 CRC Handbook of Chemistry and Physics, 71st Edition, 1991

15 T.R. Hull, K. Lebek, K.T. Paul, M. Pezzani and S. Messa, Fire Safety Journal, 43, 140-150, (2008). 